\title{
A study on new customer satisfaction index model of smart grid
}

\author{
Ze-San Liu ${ }^{1, \mathrm{a}}$, Zhuo $\mathrm{Yu}^{1, \mathrm{~b}}$ and Ai-Qiang Dong ${ }^{1, \mathrm{c}}$ \\ ${ }^{1}$ Beijing china-power information Technology Co. ,Ltd, \\ State Grid Information \& Telecommunication Group, Beijing, China \\ aliuzesan@sgitg.sgcc.com.cn, byuzhuo@sgitg.sgcc.com.cn, \\ cdongaiqiang@sgitg.sgcc.com.cn
}

\begin{abstract}
The smart grid has been being built by State Grid Corporation, Inevitably, which must have a profound impact on customers. Based on the famous Fornell ECSI model, a new index model called SGCSI has been established according to the characteristics of the smart grid, which created a new index evaluation system, including seven evaluation indexes and the relation among them, such as corporate image, customer expectations, perceived quality and so on. Finally, the new Model was applied in an energy company, which result has been proved that it can more objectively reflect the actual situation of the smart grid, and have a better feature of practical operation.
\end{abstract}

Keywords: ECSI; Smart Grid; Customer satisfy index; SGCSI.

\section{Introduction}

Quality service is the lifeline of the national grid company, especially the development of the smart grid, intelligent power requirements are high, the majority of electricity users demand showing a trend of diversification, power companies urgently need to improve the evaluation of customer satisfaction. State Grid Corporation issued in 2007 "State Grid Corporation of power supply service quality evaluation (Trial)", the management approach clearly points out the power supply enterprise to carry out customer satisfaction measurement of 
meaning and requirements, but it does not give a clear corporate image, customer expectations, perceived quality, perceived value, customer satisfaction, customer complaints, the specific relationship and the actual operation of customer loyalty among the seven evaluation. So it has underestimated the actual significance for the study of customer satisfaction evaluation model.

\section{Structural Equation Model}

The ECSI model is combined with the research results of Fornell method and customer satisfaction theory of econometrics. The model is essentially a multiple linear regression model. It is the customer satisfaction survey is seen as a complex decision-making problems have an impact on multi-level, multiobjective and multi-factor by a number of factors will affect customer satisfaction is embedded in a causal model, thus achieving customer satisfaction evaluation. ACSI model and ECSI model are structural equation model.

The structural equation model (Structural Equation Modeling, SEM) is a kind of Karl Joreskog and Dag Sorbom and other scholars put forward in 1970s by the statistical theory of comprehensive multivariate statistical method based on [1]. The structural equation model has the following main advantages: (1) compared with the first generation data analysis techniques, such as regression analysis, discriminant analysis, canonical correlation analysis and so on, SEM can not only study the direct effects of variables, but also reveal the indirect effects of variables; (2) the implicit variables used in SEM can filter the errors to the maximum extent; (3) SEM technology can seek the internal structure of the relationship between variables, can verify the theoretical model proposed by professionals and to be modified. In addition, SEM can visually display complex relationships among variables through the path method. In addition, SEM can visually display complex relationships among variables through the path method.

The basic principle of structural equation modeling is :assume that the causal relationship between a group of potential variables, these potential variables can be represented by a group of measured variables respectively. So a structural relationship between multiple potential variables was formed. The structural equation model by estimating the relationship between the measured variables and the latent variables verify whether the model is reasonable. Among them:

Measurement variables: refers to the direct observation and measurement of variables, also known as the explicit variable; Latent variables: refers to the direct observation can not be directly observed, but can be indirectly observed 
by measurable variables, also called implicit variables; Endogenous variable: a variable that can be explained by other variables in the model, equivalent to the dependent variable in the linear regression analysis; Exogenous variable: a variable that is determined by the factor outside the model, equivalent to the independent variable in the linear regression analysis.

SEM includes structure model and measurement model. Structural model, also known as endogenous model, is used to describe the relationship between implicit variables. The measurement model is also called exogenous model, which indicates the relationship between explicit and implicit variables. In the exogenous model, significant relationship between the variants and the hidden variants has two forms, external mode and internal mode. Each explicit variable of the external model is a simple regression relation with its implicit variable, that is, a set of explicit variables is derived from the implicit variable, which is reflected in the path graph; The hidden variable internal mode and significant variables into a multivariate linear function, reflection is a group of significant variables to form a hidden variable.

SEM technology is usually divided into two steps: validation measurement model and fitting structure model. The former is accomplished by confirmatory factor analysis (CFA), and the latter is carried out by means of path analysis of hidden variables. The task of CFA is to identify whether a set of implicit variables are derived from the correlation between the corresponding explicit variables and all the hidden variables. The path analysis method is the main method of multiple regression and correlation analysis, such as ordinary multiple regression, principal component regression and partial minimum regression etc..

The structural equation between the latent variables in the model can be expressed as:

$$
\begin{aligned}
& \eta=\beta \eta+\gamma \xi+e \\
& Y=\lambda_{y} \eta+e_{y} \\
& X=\lambda_{x} \xi+e_{x}
\end{aligned}
$$


Here $\eta$ vector elements $\eta_{i}$ corresponding to each of the potential variables, the quality of perception is $\eta_{1}$, expectations are $\eta_{2}$, value perception is $\eta_{3}$, SGCSI is $\eta_{4}$, customer loyalty is $\eta_{5}$, customer complaint is $\eta_{6}$; Each element of the vector $\xi, \xi_{i}$ corresponding to the respective exogenous variables ,( In this model, there is only one exogenous variable, which is the image) these linkages exogenous variables and endogenous variables are represented by linear equations (1-1), where $\gamma$ represents the impact of exogenous variables on the endogenous variables, $\beta$ represents a number of other endogenous variables within Effect of raw variables ; $\mathrm{X}, \mathrm{Y}$ is the observed variables,$\lambda_{x}$ is the effect of $\xi$ on the $\mathrm{X}, \lambda_{y}$ is the impact on $\mathrm{Y}$ of $\eta, e, e_{x}, e_{y}$ represents the error term structural equation.

Equations (2) and (3) are shown in the model to indicate the relationship between latent variables and measured variables. By this model, the latent variables can be defined by the observation variables, namely, the latent variables are represented by a variety of specific indicators.

The relationship between the observed and the non observed variables is represented by a path map of SEM. An ellipse or a circle indicates a potential variable, and a rectangular or square representation of the measured variable. The residual error is always no observed, so it is expressed in an oval or circular shape. The correlation coefficient and covariance are expressed by two direction arrows, which indicate that there is no clear direction of causality.

Based on the electricity customer satisfaction model, the company AMOS software platform shows the derived model. 


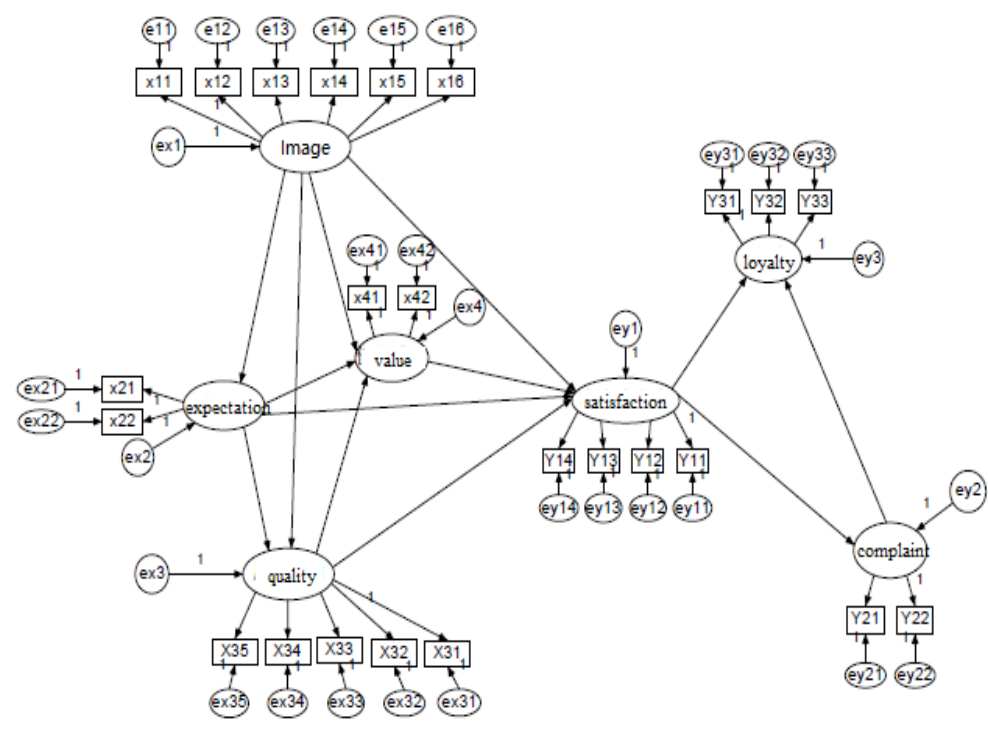

Fig 1 Model is derived using AMOS software

In Figure 1 image, customer expectation, perceived value, perceived quality, customer satisfaction, customer complaint and customer loyalty are implicit variables, which are potential variables. Indicators X11, X12, x113, Y22 and so on are the significant variables, that is, measured variants: e11, e12, ex21, ex22 etc, represents the error term. Each implicit variable is measured indirectly through a set of explicit variables. Where: X11 is the popularity of the public; X12 is the importance of social welfare level; $x 13$ is attached to the customer level; $\mathrm{x} 14$ is to ensure the high quality of power supply; $\mathrm{x} 15$ is to provide a high level of power supply service quality level; $\mathrm{x} 16$ is the service brand image and social cognition level; X21 is ideal for customers' expectations of the power supply service quality; X22 is a client of power supply service quality acceptable quality expectations; X31 is the customer evaluation on reliability of power supply; X32 is the customer evaluation of power quality; $x 33$ is customer evaluation of service quality attributes; X34 is the customer evaluation on different service channels; customer evaluation is $\mathrm{X} 35$ for different services; $\mathrm{x} 41$ is the evaluation of the power supply enterprise performance; X42 is compared with other service industry experience; Y11 is a client of the power supply / overall evaluation of service quality; Y12 Meet customer expectations; Y13 is compared with other regional utilities and differences; Y14 is with power last year, compared to the difference; y21 is the annual frequency of customer complaints; Y22 is the annual customer complaints frequency; Y31 is recommended by the will of the electric; Y32 
possibility to other energy instead of electricity. Y33 is degree of confidence on the development of provincial grid companies.

Latent variable model can be expressed as the following equations:

$$
\left(\begin{array}{l}
\eta_{1} \\
\eta_{2} \\
\eta_{3} \\
\eta_{4} \\
\eta_{5} \\
\eta_{6}
\end{array}\right)=\left(\begin{array}{cccccc}
0 & \beta_{12} & 0 & 0 & 0 & 0 \\
0 & 0 & 0 & 0 & 0 & 0 \\
\beta_{31} & \beta_{32} & 0 & 0 & 0 & 0 \\
\beta_{41} & 0 & \beta_{43} & 0 & 0 & 0 \\
0 & 0 & 0 & \beta_{54} & 0 & 0 \\
0 & 0 & 0 & 0 & \beta_{64} & \beta_{65}
\end{array}\right) \cdot\left(\begin{array}{c}
\eta_{1} \\
\eta_{2} \\
\eta_{3} \\
\eta_{4} \\
\eta_{5} \\
\eta_{6}
\end{array}\right)+\left(\begin{array}{c}
\gamma_{1} \\
\gamma_{2} \\
0 \\
\gamma_{4} \\
0 \\
0
\end{array}\right)+\left(\begin{array}{c}
e x_{1} \\
e x_{2} \\
e x_{3} \\
e x_{4} \\
e x_{5} \\
e x_{6}
\end{array}\right)
$$

The external measurement model can be expressed as the following equations (5):

$$
\left(\begin{array}{l}
x_{11} \\
x_{12} \\
x_{13} \\
x_{14} \\
x_{15} \\
x_{16}
\end{array}\right)=\left(\begin{array}{l}
\lambda_{1} \\
\lambda_{2} \\
\lambda_{3} \\
\lambda_{4} \\
\lambda_{5} \\
\lambda_{6}
\end{array}\right) \cdot \xi+\left(\begin{array}{l}
e_{11} \\
e_{12} \\
e_{13} \\
e_{14} \\
e_{15} \\
e_{16}
\end{array}\right)
$$

Internal measurement model based on quality perception (Due to the length of the space, the other endogenous variables of the model are similar, not listed in this one paper), Specific can be expressed as the following equations (6):

$$
\left(\begin{array}{l}
x_{31} \\
x_{32} \\
x_{33} \\
x_{34} \\
x_{35}
\end{array}\right)=\left(\begin{array}{l}
\lambda_{x 31} \\
\lambda_{x 32} \\
\lambda_{x 33} \\
\lambda_{x 34} \\
\lambda_{x 35}
\end{array}\right) \cdot \eta_{1}+\left(\begin{array}{l}
e x_{31} \\
e x_{32} \\
e x_{33} \\
e x_{34} \\
e x_{35}
\end{array}\right)
$$




\section{Comparative Analysis of LISREL and PLS Evaluation SGCSI Principle}

In SEM technology, partial least squares (PLS) and linear structure relation (LISREL) are the two techniques for estimating the parameters of SEM model with the highest frequency. At present, it has been the comparison between the two methods to estimate the parameters of the CSI model. For the CSI model, the application of the PLS method almost completely ruled the CSI evaluation market, and CSI evaluation LISREL example is relatively small. But at the theoretical level, the LISREL and PLS which method is more suitable to estimate the CSI model of the controversy continues, this argument is expressed in a comprehensive comparison of LISREL and PLS technologies.

PLS is a new kind of multivariate statistical analysis technique[4]. The theory consists of two parts: PLS regression and PLS path modeling. The main use of the parameter estimation of CSI model is the PLS path modeling method, and the role of PLS regression in the evaluation of CSI is to eliminate the danger of multiple co linearity between the hidden variables.

PLS path modeling structural equation and LISREL model structural equation, after each hidden variables, we can estimate the parameters of the structural equation, the method is general multivariate regression, we can also use PLS regression or other partial regression approach to estimate the parameters of the structural equation. Since the CSI model, between the antecedents and consequences of customer satisfaction variables generally exist phenomenon of multicollinearity, this chapter uses PLS regression to estimate the path parameter structure model.

Validation of the PLS model includes verification of the structural model and the measurement model. Determine the structure model parameters' significance level can be used by ordinary $t$ test data or use cross validation method; for the comprehensive relationship between the implicit variables and the corresponding explicit variables, the cross validation method of blindfolding is generally used.

In narrow sense, SEM is often expressed as a linear structure relation model LISREL (linear structural relationship). The advantage of LISREL modeling based on covariance fitting is the verification, modification and validation of the model. Some of the main testing methods and fitting indicators are: Chi square test and a number of fitting indicators test [5].

Generally believed that the PLS method is based on extraction with strong interpretation and prediction ability, the data distribution is not strictly required and the sample size is small and, and based on covariance fitting and LISREL method of data distribution has certain requirements and the need for large 
enough samples, its main function is explored the model's validation. Customer satisfaction index models in many countries prefer PLS estimation.

PLS and LISREL provide a unique advantage for the evaluation of SGCSI. Among them, the LISREL method based on covariance fitting is a strong theoretical basis for estimating and testing SGCSI model, the PLS path method based on component extraction provides a means and guarantee for the practical prediction and application of SGCSI model. But it is a pity that both of them have some disadvantages behind advantages of the evaluation of SGCSI. LISREL on the evaluation of the distribution of data requirements are more stringent, while the PLS data distribution requirements loose, but the weak fit of the model will give the hidden variables estimation the risk of failure. Therefore, in China's market economic system is not perfect, and the consumer behavior is still lack of a large number of empirical research case, this chapter uses the analysis method of PLS combined with LISREL. Balanced build model SGCSI not only needs the theory strength verification, but also need SGCSI accurate prediction effect, in order to obtain more accurate customer satisfaction index.

\section{Test Results of SGCSI Model}

\section{Validation criteria}

The model of the establishment on the relevant theory is set up, which need to further test. Table 1 is the commonly used AMOS software output of the fitting index and standard. Table:C.R. is the estimated value of the regression coefficient divided by its standard error, called the critical ratio. If the absolute value of the critical ratio is greater than 1.96 , the absolute value of the estimate is significant.

CMIN/DF is the minimum sample difference divided by degrees of freedom, called the relative chi square or the standard Chi square. When the relative chi square is greater than 2 or 3 , the conservative use is required to reject the model.

CFI (comparative fit index) called comparative fit index CFI close to 1 indicates that the fitting is very good, and its value greater than 0.90 indicates that the model can be accepted.

RMSEA (Root Mean Square Error of Approximation) is known as the root mean square approximation error. If RMSEA is less than or equal to 0.1 , the representation of the model is good; less than or equal to 0.05 , the characterization of the model is very good; less than or equal to 0.01 , the characterization of the model fit best. 
Table 1 Fit index and evaluation standard

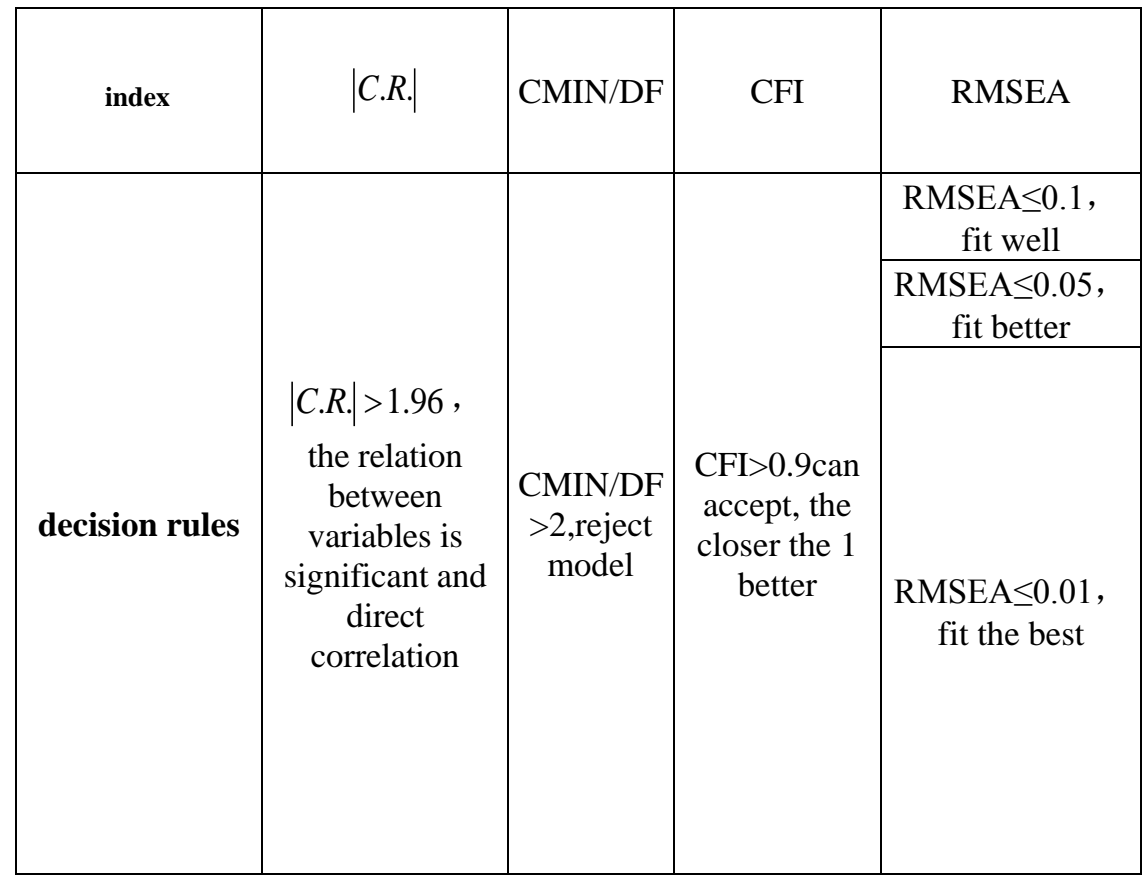


Validation Results The Verification Results are Shown in Table 2:

Table 2(a) Path coefficient calculation results

\begin{tabular}{|c|c|c|c|c|c|}
\hline & & & Estimate & S.E. & C.R. \\
\hline expectation & $<---$ & image & 0.351 & 0.068 & 5.162 \\
\hline $\begin{array}{l}\text { perceived } \\
\text { quality }\end{array}$ & $<---$ & image & 0.555 & 0.133 & 4.173 \\
\hline $\begin{array}{l}\text { perceived } \\
\text { value }\end{array}$ & $<--$ & image & 0.265 & 0.094 & 2.820 \\
\hline $\begin{array}{l}\text { perceived } \\
\text { quality }\end{array}$ & $<---$ & expectation & -0.369 & 0.091 & -4.055 \\
\hline $\begin{array}{l}\text { perceived } \\
\text { value }\end{array}$ & $<--$ & expectation & -0.392 & 0.156 & -2.513 \\
\hline $\begin{array}{c}\text { customer } \\
\text { satisfaction }\end{array}$ & $<--$ & expectation & -0.294 & 0.167 & -1.760 \\
\hline $\begin{array}{l}\text { perceived } \\
\text { value }\end{array}$ & $<--$ & $\begin{array}{l}\text { perceived } \\
\text { quality }\end{array}$ & 0.541 & 0.157 & 3.446 \\
\hline $\begin{array}{l}\text { customer } \\
\text { satisfaction }\end{array}$ & $<--$ & image & 0.211 & 0.124 & 1.702 \\
\hline $\begin{array}{l}\text { customer } \\
\text { satisfaction }\end{array}$ & $<--$ & $\begin{array}{l}\text { perceived } \\
\text { quality }\end{array}$ & 0.511 & 0.155 & 3.297 \\
\hline $\begin{array}{c}\text { customer } \\
\text { satisfaction }\end{array}$ & $<--$ & perceived value & 0.487 & 0.049 & 9.939 \\
\hline complaint & $<--$ & $\begin{array}{l}\text { customer } \\
\text { satisfaction }\end{array}$ & 0.538 & 0.164 & 3.280 \\
\hline loyalty & $<---$ & $\begin{array}{l}\text { customer } \\
\text { satisfaction }\end{array}$ & 0.512 & 0.241 & 2.124 \\
\hline loyalty & $<--$ & complaint & -0.236 & 0.102 & -2.314 \\
\hline Y11 & $<--$ & $\begin{array}{l}\text { customer } \\
\text { satisfaction }\end{array}$ & 1.000 & & \\
\hline Y12 & $<---$ & $\begin{array}{l}\text { customer } \\
\text { satisfaction }\end{array}$ & 0.564 & 0.211 & 2.673 \\
\hline Y13 & $<--$ & $\begin{array}{l}\text { customer } \\
\text { satisfaction }\end{array}$ & 0.457 & 0.121 & 3.777 \\
\hline
\end{tabular}


Table 2(b) Path coefficient calculation results

\begin{tabular}{|c|c|c|c|c|c|}
\hline & & & Estimate & S.E. & C.R. \\
\hline Y14 & $<---$ & $\begin{array}{c}\text { customer } \\
\text { satisfaction }\end{array}$ & 0.367 & 0.174 & 2.109 \\
\hline Y31 & $<---$ & loyalty & 1.000 & & \\
\hline Y32 & $<---$ & loyalty & 0.622 & 0.156 & 3.987 \\
\hline Y33 & $<---$ & loyalty & 0.983 & 0.107 & 9.187 \\
\hline X31 & $<---$ & $\begin{array}{l}\text { perceived } \\
\text { quality }\end{array}$ & 1.000 & 0.231 & 4.329 \\
\hline X32 & $<---$ & $\begin{array}{l}\text { perceived } \\
\text { quality }\end{array}$ & 0.602 & 0.203 & 2.966 \\
\hline X33 & $<---$ & $\begin{array}{l}\text { perceived } \\
\text { quality }\end{array}$ & 0.864 & 0.264 & 3.273 \\
\hline X34 & $<---$ & $\begin{array}{l}\text { perceived } \\
\text { quality }\end{array}$ & 0.714 & 0.341 & 2.094 \\
\hline X35 & $<---$ & $\begin{array}{l}\text { perceived } \\
\text { quality }\end{array}$ & 0.826 & 0.298 & 2.772 \\
\hline $\mathrm{x} 22$ & $<---$ & expectation & 1.000 & & \\
\hline $\mathrm{x} 21$ & $<---$ & expectation & 0.626 & 0.235 & 2.6 \\
\hline $\mathrm{x} 41$ & $<---$ & $\begin{array}{l}\text { perceived } \\
\text { value }\end{array}$ & 1.000 & & \\
\hline$x 42$ & $<---$ & $\begin{array}{l}\text { perceived } \\
\text { value }\end{array}$ & 1.641 & 0.241 & 6.809 \\
\hline $\mathrm{x} 11$ & $<---$ & image & 1.000 & & \\
\hline $\mathrm{x} 12$ & $<---$ & image & 0.687 & 0.252 & 2.726 \\
\hline $\mathrm{x} 13$ & $<--$ & image & 1.721 & 0.646 & 2.664 \\
\hline x14 & $<---$ & image & 0.466 & 0.377 & 1.236 \\
\hline $\mathrm{x} 15$ & $<---$ & image & 1.230 & 0.213 & 5.775 \\
\hline $\mathrm{x} 16$ & $<--$ & image & 0.521 & 0.152 & 3.428 \\
\hline Y22 & $<---$ & complaint & 1.000 & & \\
\hline Y21 & $<--$ & complaint & 0.781 & 0.174 & 4.489 \\
\hline
\end{tabular}

Table 2 Estimate is the regression coefficient, that is, the path coefficient of the model with the arrow. In order to identify the model, part of the coefficients in the model identification has been fixed to 1. S.E. is the standard error of path coefficient. 
Table 3 Result of model goodness of fit

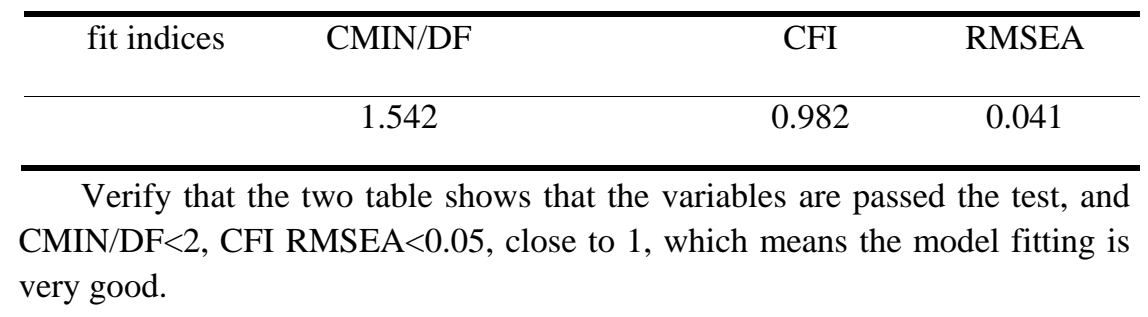

\section{Conclusion}

This chapter describes the research status of customer satisfaction were reviewed and analyzed, drawing on ACSI, ECSI and CCSI model based on the combination of the characteristics of China's power industry, constructed the index system of provincial electricity company 's customer satisfaction comprehensive evaluation and SGCSI model ; designed the corresponding questionnaire; used analytic hierarchy process to calculate the weight vector of index system; used the single element correction method to deal with the requirements are not satisfied with the consistency of the judgment matrix, have achieved the desired effect; After deeply analyzing the characteristics of SGCSI structural equation, we choose LISREL and PLS to validate the model, and obtain a more accurate index of satisfaction; We use the model built on the 14 city of the company's SGCSI power supply company conducted in-depth, comprehensive evaluation and analysis, to provide a scientific basis for the management of the decision.

\section{References}

[1] Wei Zhao, Kang Yao, Songling Huang. Thinking of Advanced Measurement Architecture on Smart Grid [J]. Electrical Measurement \& Instrumentation, 2010, 47(5): 1-7

[2] Junyu Yao, Junyong Liu, Youbo Liu. Our Development Strategy and Opportunity on the Smart Marketing [J]. Electric Power Automation Equipment, 2010, 23(3):129-133

[3] Haozheng Qiu, Bifang Lin. The Theory and Application of Structural Equation Model [M]. Beijing: China Light Industry Press, 2008:87 103

[4] Jietai Hou. Structural Equation Model and Application[M]. Beijing: Education Science Press, 2004:87 97

[5] Chin, W. W. PLS is to LISREL as Principal Components Analysis is to Common Factor Analysis[J]. Technology Studies, 1995, (2):315-319 